REVISTA DE GEOCIÊNCIAS DO NORDESTE

Northeast Geosciences Journal

v. $6, n^{\circ} 2(2020)$

ISSN: $2447-3359$

https://doi.org/10.21680/2447-3359.2020v6n2ID20406

\title{
PLANEJAMENTO AMBIENTAL EM BACIAS HIDROGRÁFICAS SEMIÁRIDAS DO NORDESTE BRASILEIRO
}

\section{Ernane Cortez Lima ${ }^{1}$}

${ }^{1}$ Doutor em Geografia, Centro de Ciências Humanas, Universidade Estadual Vale do Acaraú (UVA), Sobral/CE, Brasil. ORCID: https://orcid.org/0000-0002-1744-6928

Email: ernanecortez@hotmail.com

\section{Resumo}

O planejamento categorização e enquadramento de bacias hidrográficas semiáridas no nordeste brasileiro torna-se imprescindível tendo como escopo assegurar às águas qualidade compatibilizada com os usos mais diversificados a que estas forem destinadas. As pesquisas voltadas para o planejamento e ordenamento territorial através de estudos ambientais integrados no contexto de bacias hidrográficas, podem ser fundamentais para as políticas públicas que visem um melhor uso e ocupação do território, procurando adequar-se ao desenvolvimento sustentável. Desta maneira a Política Nacional de Recursos Hídricos vem sendo aprimorada por meio da legislação dos recursos hídricos através da apoio de órgãos estaduais que estabelecem segurança à política dos mananciais dos estados da federação brasileira.

Palavras-chave: Bacias hidrográficas; Planeamento ambiental; Semiárido.

\section{ENVIRONMENTAL PLANNING IN SEMIARID WATERSHEDS IN NORTHEASTERN BRAZIL}

\section{Abstract}

The planning categorization and framing of semiarid watersheds in northeastern Brazil is essential to ensure the quality waters compatible with the most diversified uses to which they are destined. Research focused on planning and spatial planning through environmental studies integrated in the context of river basins, can be fundamental for public policies aimed at better use and occupation of the territory, seeking adapt to sustainable development. In this way, the National Water Resources Policy has been improved through water resources legislation through the support of state agencies that establish security for the policy of the springs of the states of the Brazilian federation.

Keywords: Watersheds; Environmental planning: Semi-arid.

\section{PLANIFICACIÓN AMBIENTAL EN CUENCAS HIDROGRÁFICAS SEMIARIDAS EN EL NORESTE BRASILEÑO}

\section{Resumen}

La categorización de planificación y el encuadre de cuencas hidrográficas semiáridas en el noreste de Brasil es esencial para garantizar las aguas de calidad compatibles con los usos más diversificados a los que están destinadas. La investigación centrada en la planificación y la planificación espacial a través de estudios ambientales integrados en el contexto de las cuencas hidrográficas, puede ser fundamental para las políticas públicas encaminadas a un mejor uso y ocupación del territorio, buscando adaptarse al desarrollo sostenible. De esta manera, la Política Nacional de Recursos Hídricos se ha mejorado a través de la legislación sobre recursos hídricos a través del apoyo de organismos estatales que establecen seguridad para la política de los manantiales de los estados de la federación brasileña.

Palabras Claves: Cuencas hidrográficas; Planificación ambiental; Semiáridas.

\section{INTRODUÇÃO}

Este trabalho tem como objetivo apresentar como se dá o planejamento ambiental em bacias hidrográficas semiáridas do nordeste brasileiro de acordo com a Política Nacional de Recursos Hídricos. Para Lima (2012) a questão principal para o planejamento em bacias hidrográficas é partir do uso e ocupação do solo, constatando os conflitos existentes entre a produção e os componentes de gestão dos recursos hídricos que venha subsidiar a questão ambiental. Os conflitos têm ocorrido no campo das políticas setoriais contrárias como também incoerentes encravadas no poder municipal, estadual e federal, agravando-se quando existem poderes diferenciados.

Partindo do que foi alocado há de se observar como o planejamento ambiental será implantado numa escala local, das pequenas comunidades, dos povoados e das cidades, permitindo assim uma apropriação de conhecimento pelas comunidades acerca de como todo esse processo de planejamento poderá vir a ser implementado e absorvido.

A questão de enquadramento de bacias hidrográficas é primordial do ponto de vista econômico e social, sobretudo 
quando se refere aos monitoramentos quantitativos e qualitativos dos recursos hídricos do nordeste brasileiro, o qual possui a maioria dos seus mananciais no semiárido. Destaque para o estado do Ceará através da implementação de sua Política Estadual de Recursos Hídricos por meio da lei 11.996, de 24/07/1992. Dessa forma a gestão integrada e descentralizada por bacia hidrográfica ao lado da participação da sociedade tem contribuído de modo positivo com a política dos recursos hídricos.

\section{METODOLOGIA}

Manejo de bacias hidrográficas refere-se ao que é especificado pelo plano diretor, sendo a viabilização de práticas socioeconômicas, ambientais, hídricas, edáficas, botânicas e faunísticas Rocha (2007). No entanto, há outras práticas ou aproveitamentos do manejo de bacias hidrográficas, como: Estudos de Impacto Ambiental - EIA/RIMA, planos de controle ambiental, diagnósticos físicos e ambientais, como também diagnósticos socioeconômicos.

Por meio desses manejos podem ser realizadas pesquisas e estudos relacionados, tais como: degradação ambiental, índice de desmatamento; índice de precipitação pluviométrica dentro da bacia, turbidez das águas; degradação ecológica; lançamento in natura de esgotos domésticos e efluentes líquidos industriais; disposição inadequada de lixos urbanos; erosão do solo e assoreamento de material carreado; uso de defensivos agrícolas, etc.

Vale ressaltar que o plano diretor é instrumento legal de planejamento ambiental e gestão que tem como objetivo, a melhoria da qualidade de vida da população de forma mais generalizada. Trazendo consigo o ordenamento territorial através do crescimento econômico, a expansão do território como também a conservação e preservação ambiental. $\mathrm{O}$ manejo é a ferramenta básica de orientar, planejar, sugerir, preparar ações para o uso da terra e dos recursos naturais da bacia sem danos ao solo e água.

Para Santana (EMBRAPA) 2003 O manejo integrado de bacias hidrográficas visa tornar compatível produção com preservação ambiental, buscando adequar a interveniência antrópica às características biofísicas dessas unidades naturais (ordenamento do uso/ocupação da paisagem, observadas as aptidões de cada segmento e sua distribuição espacial na respectiva bacia hidrográfica), sob gestão integrativa e participativa, de forma que sejam minimizados impactos negativos e se garanta o desenvolvimento sustentado (Souza \& Fernandes, 2000). Busca integrar esforços das diversas instituições presentes nas várias áreas de conhecimento, a fim de que todas as atividades econômicas dentro da bacia sejam desenvolvidas de forma sustentável e trabalhadas integradamente. Ainda segundo Santana (EMBRAPA) 2003 O manejo integrado de bacias hidrográficas pressupõe alguns princípios fundamentais.

\subsection{Unidade de planejamento}

O conceito de manejo integrado de bacias hidrográficas implica planejar e inserir as práticas conservacionistas considerando-se o contexto das bacias e não nas propriedades isoladas. A unidade de planejamento passa a ser a bacia hidrográfica. Cada bacia hidrográfica se conecta a outra de maior tamanho, compondo, em relação à última, uma sub-bacia. As bacias hidrográficas maiores são resultantes do conjunto de pequenas bacias. Por conseguinte, os trabalhos de manejo de bacias hidrográficas devem ser iniciados, preferencialmente, nas bacias de menor porte.

\subsection{Enfoque hidro- agrícola}

O planejamento de bacias tem trabalhado no sentido unilateral: ora priorizando o aspecto hídrico, ora priorizando o uso agrícola. Sem dúvida o aspecto hídrico tem grande relevância, mas não se pode esquecer o produtor rural que habita na bacia hidrográfica são trata-se de comunidades ribeirinhas e tradicionais, e necessitam de renda para sua sobrevivência. Contudo, as medidas de manejo integrado de bacias hidrográficas devem transcender o ponto de vista puramente agrícola, refletindo em garantia de abastecimento hídrico, tanto em quantidade quanto em qualidade, para essas populações como também, processamentos industriais e vida útil de reservatórios, para geração de energia e fonte de lazer. Dentro desse contexto, o espaço rural adquire relevância não só na produção de alimentos e fibras, mas também como "produtor" de água em quantidade e qualidade suficientes, para utilização múltipla por outros segmentos da sociedade.

\subsection{Capacidade de suporte ambiental}

O uso e a ocupação do espaço são condicionados pelas características intrínsecas de cada bacia hidrográfica. Esta por sua vez determina as potencialidades e limitações para as diversas modalidades de uso/ocupação e a visualização de possíveis conflitos de interesses. Versa na identificação do espaço geográfico e dos recursos naturais da bacia, tendo como base a integração dos componentes biofísicos, bioquímicos e minerais dos ecossistemas e suas respectivas potencialidades e limitações, determinando-se sua capacidade de suporte.

\subsection{Os quais envolve}

- Identificação dos ecossistemas, evidenciando suas potencialidades e limitações para as atividades econômicas, tais como: agropecuária, turismo e mineração.

- Identificação de mananciais para abastecimento público.

- Identificação de áreas para recuperação ambiental.

- Fundamentos para a elaboração do plano de uso do espaço rural. Para garantir a conservação do solo e da água, cada gleba de terra da propriedade ou da sub-bacia hidrográfica deve ser explorada de acordo com sua capacidade de uso: mata, pastagens e lavouras, cada uma no seu devido lugar.

\section{RESULTADOS E DISCUSSÃO}

O planejamento ambiental é um procedimento contínuo que tem como objetivos conservar, preservar e adequar os 
empreendimentos ao meio ambiente de maneira a assegurar a qualidade ambiental.

O planejamento de bacias hidrográficas é respaldado pela Lei Federal nº 9.433 (BRASIL, 1997), que institui a política Nacional de Recursos Hídricos e cria o Sistema Nacional de Gerenciamento de Recursos Hídricos. Conforme Braga (2009), um dos fundamentos do Sistema Nacional de Recursos Hídricos é o reconhecimento de que a bacia hidrográfica é uma unidade básica de gestão. Ao mesmo tempo, considera como instrumento dessa política os planos de recursos hídricos, que devem ser formulados para o País e por Estado, dando sustentação ao plano de bacia.

O planejamento de recursos hídricos, segundo a Lei Federal $n^{\circ}$ 9.433/97, Seção I, Art. $7^{\circ}$, são considerados de médio a longo prazos e os mesmos devem abordar:

I. diagnóstico da situação atual dos recursos hídricos;

II. análise de alternativas de crescimento demográfico, de evolução de atividades produtivas e de modificações dos padrões de uso e ocupação do solo;

III. balanço entre disponibilidade e demandas futuras dos recursos hídricos, em quantidade e qualidade, com identificação de conflitos potenciais;

IV. metas de racionamento de uso, aumento da quantidade e melhoria da qualidade dos recursos hídricos disponíveis;

V. medidas a serem tomadas, programas a serem desenvolvidos e projetos a serem implantados, para o atendimento das metas previstas;

VI. prioridades para outorga de direitos de uso dos recursos hídricos;

VII. diretrizes e critérios para cobrança pelo uso dos recursos hídricos;

VIII. propostas para criação de áreas sujeitas a restrições de uso, com vistas à proteção dos recursos hídricos.

A elaboração do planejamento ambiental em bacias hidrográficas semiáridas deve seguir as seguintes fases: do diagnóstico, do prognóstico, da compatibilização, da formulação, das consultas e das propostas organizacionais de implantação. Ressalta-se a grande interface que o plano de recursos hídricos proporciona com outorga, a cobrança, o licenciamento ambiental, o zoneamento ambiental, o enquadramento dos corpos d'água e também com as instâncias de decisão colegiada.

O diagnóstico ambiental é a instrumento necessário que prioriza a identificação e a caracterização dos sistemas naturais homogêneos existentes na área da pesquisa. O sistema funciona como uma unidade de organização do ambiente natural susceptível a demarcação. Assim cada sistema constitui uma unidade ambiental existindo uma relação harmônica entre os componentes a ele próprios, constituídos de potenciais e restrições de seus recursos.

Embora haja eficácia do diagnóstico ambiental citado, há de se empregar um outro diagnóstico o qual abordará os aspectos demográficos e socioeconômicos das populações e comunidades tradicionais e ribeirinhas que habitam a área da bacia hidrográfica. Refere-se a demografia, núcleos populacionais peculiares, saúde, educação, habitação, tipos de trabalhos, etc. Segundo esse ordenamento, levanta-se informações em órgãos federais, estaduais e municipais: IBGE, Ministério do Trabalho, IPLANCE, Secretarias dos municípios inseridos na área em estudo; de educação, de saúde, de infraestrutura, de administração, etc.

O planejamento e o gerenciamento de bacias hidrográficas devem:

Em primeiro plano: incorporar todos os recursos ambientais da área de drenagem e não apenas o hídrico;

Em segundo plano: adotar uma abordagem de integração dos aspectos ambientais, sociais, econômicos e políticos com ênfase nos primeiros;

Em terceiro plano: incluir os objetivos de qualidade ambiental para utilização dos recursos, procurando aumentar a produtividade dos mesmos e, ao mesmo tempo, diminuir os impactos e riscos ambientais na bacia de drenagem. Lorandi \& Cançado (2008).

Para que haja um planejamento ambiental adequado em bacias hidrográficas semiáridas do nordeste brasileiro deve-se seguir determinadas regras:

- A análise das potencialidades e riscos próprios à utilização dos recursos naturais para o desenvolvimento apropriado. Por meio do planejamento, uma localidade é percebida conforme seu potencial de uso levando-se em conta a questão ambiental.

- $\quad$ Para Franco (2001), o planejamento ambiental propõe três princípios da ação do homem sobre o meio ambiente: preservação, recuperação e conservação. O primeiro propõe a não interferência em determinados locais, estes devem permanecer como estão. $\mathrm{O}$ segundo busca estancar as agressões e recuperar ambientes degradados. $\mathrm{O}$ terceiro permite o uso do meio pelo homem, mas com limites, fazendo com que o mesmo não seja degradado.

Ressalte-se que: $O$ planejamento ambiental em bacias hidrográficas semiáridas é instrumento primordial para o processo de gestão ambiental. Este ajuda no processo de articulação das forças políticas como também nas tomadas de decisões.

Tratando-se da Drenagem Intermitente Sazonal Exorréica do Nordeste Brasileiro já que o tema aborda bacia hidrográfica semiárida do nordeste brasileiro, de acordo com Ab' Saber O domínio das caatingas tem uma hidrologia típica de região semiárida intertropical. Em seu conjunto a região possui uma drenagem exorréica, dotada de cursos d'água intermitentes sazonais. Portanto, o autor indica que os canais fluviais mesmo temporários chegam a alcançarem o oceano. Nos anos reconhecidamente secos a drenagem passa a ter um funcionamento tipicamente esporádico, nas áreas mais afetadas pela escassez e irregularidade das precipitações. Desta forma, os rios do domínio semiárido brasileiro funcionam como cursos intermitentes estacionais por diversos anos. Bruscamente, porém, com o advento de um ano árido, os mesmos rios, normalmente intermitentes, passam a se comportar como cursos d'água esporádicos do tipo "ueds" ou "flash flood", É de se notar que este caráter temporário de "rios desérticos", adquirido pelos cursos d'água nordestinos nas grandes secas, é tanto mais pronunciado para a nervura menor da drenagem do que para os rios principais... Nessa frase Ab'Sáber deixa claro que existem muitos pequenos riachos, sendo esses associados à pouca infiltração e maior escoamento da drenagem ligada ao embasamento cristalino. Isto porque, os pequenos cursos d'água nascidos nas encostas de serras ou desenvolvidos nas depressões interplanálticas sertanejas - 
alimentados por chuvas de "trovoadas" - têm uma tendência natural para o regime de rios efêmeros ou esporádicos. Os rios adquirem o caráter de intermitentes sazonais quase que exclusivamente por se beneficiarem das alternâncias regionais da alimentação fornecida pelo conjunto das pequenas sub-bacias hidrográficas. Nas épocas de grandes chuvas, correspondentes aos anos de máxima precipitação, ocorre sempre uma superalimentação dos cursos d'água principais, criando-se o fenômeno paradoxal das inundações. Estas, por seu turno, circunscrevem-se apenas aos períodos mais chuvosos do ano, através de sucessivos "picos", após os quais os rios perdem de novo, por 5 ou 6 meses a sua correnteza. Portanto, a despeito das grandes chuvas de verão-outono, os rios nordestinos nunca deixam de ser intermitentes sazonais.

\section{CONSIDERAÇÕES FINAIS}

Ficou claro que o planejamento ambiental em bacias hidrográficas semiáridas do nordeste brasileiro precisa de maior enfoque através do poder público e de iniciativas conjuntamente com as comunidades ribeirinhas tradicionais e urbanas procurando intercambiar e facilitar a comunicação entre governo e população. Demonstrando através de cursos de capacitação que realmente chegue a quem precisa aprimorar ou mesmo reconhecer problemas em bacias hidrográficas que poderão serem amenizados e/ou mesmo resolvidos num contexto local levando a experiência positiva para outros setores da bacia. O plano de manejo só tem a oferecer de maneira bastante significativa subsídios ao desenvolvimento sustentável. Geralmente áreas de bacias hidrográficas são muito extensas e demandam tempo para averiguação de potencialidades e fragilidades as quais possuem, isso poderá ser melhorado por meio geotecnologias através de imagens de satélite landsat 8,9 que vieram interceder de fora acertada facilitando e ao esmo tempo auxiliando no trabalho de campo.

\section{REFERÊNCIAS}

Aziz Nacib Ab'Sáber. O domínio morfoclimático semiárido das caatingas brasileiras. Instituto de Geografia, Universidade de São Paulo, 1974.

BRASIL. Lei $n^{\circ}$ 9.433, de 08 de janeiro de 1997. Diário Oficial [da] República Federativa do Brasil, Brasília, DF, 09 de jan. $1997 . \quad$ Disponível em: http://www.planalto.gov.br/ccivil_03/LEIS/19433.htm. Acesso em: 21 de maio de 2013.

BRAGA, RICARDO. Instrutores para gestão ambiental e de recursos hídricos. Ed. Universitária da UFPE, 2009.

EMBRAPA. Sistema Brasileiro de Classificação de Solos. 2. ed. Rio de Janeiro: Embrapa Solos, 2006. 306 p.

FRANCO, Maria de Assunção Ribeiro. Planejamento ambiental para a cidade sustentável. 2 ed. São Paulo: Anna blume: FAPESP, 2001;

LIMA, Ernane Cortez. Planejamento ambiental como subsídio para gestão ambiental da bacia de drenagem do açude
Paulo Sarasate Varjota - Ceará. Fortaleza, 2012. 201f. Tese (Doutorado em geografia) - Universidade Federal do Ceará, UFC, 2012.

LORANDI, R \& CANÇADO, C. J. Parâmetros físicos para gerenciamento de bacias hidrográficas. In: SCHIAVETTI, A.; CAMARGO, A. F. M. Conceitos de bacias hidrográficas: teorias e aplicações. Ilhéus: Editus, 2008. cap. 2 .

ROCHA, J. S. M. \& Kurtz, S. M. J. M. Manual de Manejo Integrado de Bacias Hidrográficas, Santa Maria: Edições UFSM CCR/UFSM, 2007.

SANTANA, M. O.; RIBEIRO, A.; SEDIYAMA, G. C. Sistema de geoespacialização da demanda de irrigação suplementar para o estado de Minas Gerais. I: Descrição Revista Brasileira de Engenharia Agricola. 2003.

Recebido em: 15/04/2020

Aceito para publicação em: 11/08/2020 